\title{
Pressupostos e derivações didáticas da psicologia genético- dialética de Henri Wallon
}

\author{
Ricardo Baratella \\ Universidade de Uberaba - UNIUBE, Brasil \\ Adriana Rodrigues \\ Universidade de Uberaba - UNIUBE, Brasil
}

\begin{abstract}
RESUMO
O presente trabalho objetiva apresentar reflexões preliminares acerca da teoria psicogenética walloniana, focalizando o desenvolvimento da pessoa completa e suas contribuições didáticas. Tomam-se, como referencial, as proposições de Henri Wallon em seu método concretomultidimensional, ancorado epistemologicamente na filosofia marxista e, mais especificamente, no materialismo dialético. Para tanto, foi realizada uma pesquisa qualitativa de cunho conceitual bibliográfico, na qual foi possível compreender a constituição do sujeito e seus desdobramentos em singularidades afetivas, cognitivas e motoras. Conclui-se que a teoria walloniana oferece fundamentos psicológicos importantes para substanciar as práticas pedagógicas e a organização do ensino-aprendizagem com vistas a proporcionar o desenvolvimento do aluno. Em suas ideias pedagógicas, Wallon sugere que a escola reflita acerca de suas dimensões sócio-políticas e aproprie-se de sua ação no movimento de transformação da sociedade.
\end{abstract}

PALAVRAS-CHAVE: Teoria walloniana. Psicogenética. Derivações didáticas.

\section{ASSUMPTIONS AND DIDACTIC DERIVATIVES OF HENRI WALLON'S GENETIC-DIALECTIC PSYCHOLOGY}

\begin{abstract}
The present work aims to present preliminary reflections on the Wallonian psychogenetic theory, focusing on the development of the complete person and his didactic contributions. The propositions of Henri Wallon in his concrete-multidimensional method, anchored epistemologically in Marxist philosophy and, more specifically, in dialectical materialism, are taken as references. Therefore, a qualitative bibliographic conceptual research was carried out, in which it was possible to understand the constitution of the subject and its unfolding in affective, cognitive and motor singularities. In conclusion that the Wallonian theory offers important psychological foundations to substantiate the pedagogical practices and the organization of teaching-learning in order to provide the development of the student. In his pedagogical ideas, he suggests that the school reflect about its socio-political dimensions and appropriate its action in the transformation movement of society.
\end{abstract}

KEYWORDS: Wallonian theory. Psychogenetics. Didactic derivations. 


\section{PRESSUPOSTOS Y DERIVACIONES DIDÁCTICAS DE LA PSICOLOGÍA GENÉTICA-DIALÉTICA DE HENRI WALLON}

\section{RESUMEN}

El presente trabajo tiene como objetivo presentar reflexiones preliminares acerca de la teoría psicogenética walloniana, enfocando el desarrollo de la persona completa y sus contribuciones didácticas. Se toman como referencial las proposiciones de Henri Wallon en su método concreto-multidimensional, anclado epistemológicamente en la filosofía marxista y, más específicamente, en el materialismo dialéctico. Para ello, se realizó una investigación cualitativa de cuño conceptual bibliográfico, en la cual fue posible comprender la constitución del sujeto y sus desdoblamientos en singularidades afectivas, cognitivas y motoras. Se concluye que la teoría walloniana ofrece fundamentos psicológicos importantes para sustanciar las prácticas pedagógicas y la organización del aprendizaje-aprendizaje con miras a proporcionar el desarrollo del alumno. En sus ideas pedagógicas, Wallon sugiere que la escuela reflexione acerca de sus dimensiones socio-políticas y se apropie de su acción en el movimiento de transformación de la sociedad.

PALABRAS CLAVE: Teoría walloniana. Psicogenética. Derivaciones didácticas.

\section{INTRODUÇÃO}

Henri Paul Hyacinthe Wallon nasceu na França em 1879 e viveu em um tempo assinalado por instabilidades sociais e turbulências políticas, cujas ideias influenciaram seu modo de pensar e ver o mundo. Morreu em Paris, local em que sempre residiu, no ano de 1962. Humanista, sonhador ou realista, aspirava a comunhão entre a teoria e a prática, direcionando seus estudos para educadores e pedagogos. Foi um expoente na Psicologia do século XX, com destaque para os estudos e pesquisas voltadas à perspectiva genética do pensamento, ou seja, buscavam explicação para a gênese da formação e desenvolvimento do psiquismo, com grande influência nos processos de ensino-aprendizagem e de todo o fazer escolar.

Para Wallon, a escola é um lugar em que se educa, mas principalmente refere-se ao espaço em que se observa e analisa a personalidade infantil. Os pressupostos teóricos wallonianos contribuíram significativamente para a Educação e uma das originalidades de sua teoria é a tentativa de verificar a criança considerando o seu desenvolvimento de forma integrada em duas vertentes, seja na unidade organismo-meio, seja em seus domínios afetivo, cognitivo e motor.

Em suas obras, Henri Wallon aponta um estudo teórico sistemático dos comportamentos infantis, com o objetivo de compreendermos algumas crianças e suas condutas. À medida que as condutas das crianças começam a se aprimorar, as reações emocionais passam a se demarcar com mais perceptibilidade e a revelarem certa estabilidade; 
dessa forma elas vão, ao mesmo tempo, "dominando" seus movimentos, tornando-os propositados, direcionados, significativos e construindo a consciência de si. Em outras palavras, o autor nos revela que um sujeito se constrói processualmente, a partir de suas interações com o meio em que vive.

O teórico ratifica a relevância da linguagem para o desenvolvimento infantil. Por meio dela, advém a substituição do objeto percebível, as representações sociais e, por meio desse fato simbólico, a criança opera sobre o que está ausente. Dessa maneira, ela se insere no "mundo dos signos", que será uma diretriz para os pensamentos, pois os signos traduzem uma forma de unir o que estava desatado, abstrair o que tinha sido simultâneo.

Nesse contexto, as emoções, antes mesmo da linguagem, são o meio aproveitado pelo recém-nascido para constituir uma afinidade com o mundo humano. Gradualmente, os movimentos de expressão, primeiramente de natureza fisiológica, evoluem até se tornarem comportamentos afetivos mais complexos, nos quais a emoção, aos poucos, resigna "chão" aos sentimentos e, em seguida, às atividades intelectuais. Impossibilitada de executar alguma coisa por si própria, a criança dispõe da emoção para provocar nos outros a participação, a mediação e a colaboração na satisfação de suas necessidades básicas, como brincar, comer, dormir e esquivar a uma atitude ou posição incômoda.

As emoções não só despontam como um conjunto de expressões e comunicação, como também exercem um papel essencial no desenvolvimento da inteligência e auxiliam ou não, a criança a pensar e a constituir relações lógicas. Nessa fase, as crianças são mais emoção que inteligência, a emoção prevalece sobre a reflexão, quadro que vai, aos poucos, transformandose, ao longo do seu desenvolvimento. Henri Wallon indica o estudo conexo do desenvolvimento, ou seja, os diversos campos funcionais nos quais se difundem as atividades infantis (afetividade, motricidade, inteligência).

Essas considerações são fundamentais para o campo educacional, notadamente da Didática, haja vista que grande parte dos educadores desconhece as suas contribuições em relação à afetividade “... já que a tendência intelectualista, generalizada na escola contemporânea, parece ignorar os determinantes afetivos e emotivos do pensamento e da conduta do/a aluno/a." (PÉREZ GOMES, 1998, p. 48). Assim, nesse artigo objetivamos um aprofundamento da teoria de Henri Wallon, focalizando as dimensões do desenvolvimento da pessoa completa e suas derivações didáticas. Para tanto, valemo-nos do aporte teórico bibliográfico em Wallon (1995) e estudiosos como Tran-thong (1987), Mahoney e Almeida (2004), Galvão (2007) entre outros. 


\section{A INFLUÊNCIA DOS FATORES ORGÂNICOS E SOCIAIS}

$\mathrm{Na}$ teoria walloniana, os fatores orgânicos constituem a primeira fase ou etapa para o desenvolvimento do pensamento; porém Wallon ressalta a significância do meio. Assim, a duração de cada estágio sofre influências das conjunturas sociais em que se insere o sujeito. Cada fase é, sincronicamente, um momento de evolução mental e sinaliza um ou alguns tipos de comportamentos. Nesse sentido, o desenvolvimento de um sujeito é percebido em sua totalidade, abarcando os múltiplos domínios funcionais e os períodos de faculdades mentais e intelectuais.

O fator biológico é mais definitivo no princípio de vida das crianças e gradativamente vai oferecendo espaço às influências do meio social. Essas influências tornam-se mais evidentes com o desenvolvimento do sujeito, e ao mesmo tempo, para a constituição da inteligência simbólica. Na trajetória que delineia a gênese da pessoa, Wallon entrelaça o ser biológico e o ser social tomados enquanto unidade e não dicotômicos, pois ele tenta romper com a dicotomia orgânico-social, até então preponderante na Psicologia e nas análises sócio-genéticas. O autor considera o organismo como uma categoria primária do pensamento, enfim, toda função psíquica conjectura um "equipamento" orgânico. Indica, contudo, que não lhe compõe uma razão satisfatória, visto que o objeto da ação mental surge do exterior, isto é, de grupos ou ambientes nos quais os sujeitos se inseriram.

O método de investigação utilizado por Wallon é denominado concretomultidimensional (TRAN-THONG, 1987), o qual foi fortemente influenciado pelos pressupostos do materialismo dialético, com a teoria das emoções enquanto centralidade e alicerce de suas obras. Para o autor, as emoções são a exterioridade da afetividade, refletem um comportamento social e adaptativo do sujeito ao seu meio, mas um adaptativo que congrega dialeticamente a universalidade e a singularidade, a emoção como representação da unidade entre significado e significante ou significado e sentido. A teoria walloniana é conhecida como psicologia da pessoa completa, pois direciona precisamente à produção de uma sabedoria psicológica que considera a totalidade da pessoa, em suas perspectivas visíveis de existência, a partir de uma perspectiva genética. Quanto a esse aspecto, é importante ressaltar que “ [...] o desenvolvimento da criança se constitui no encontro, no entrelaçamento de suas condições orgânicas e de suas condições de existência cotidiana, encravada numa dada sociedade, numa dada cultura, numa dada época." (MAHONEY, 2004, p.14). 
Para Wallon, o caminho de um estágio de desenvolvimento para outro não é uma simples ampliação, mas uma reformulação, e o ritmo pelo qual acontecem as etapas é descontínuo, caracterizado muitas vezes por interrupções, anacronismos e mudanças repentinas. Nesse sentido, pondera-se que "[..] o ritmo descontínuo que Wallon assinala ao processo de desenvolvimento infantil, assemelha-se ao movimento de um pêndulo que, oscilando entre polos opostos, imprime características próprias a cada etapa do desenvolvimento." (GALVÃO, 2007, p.47). Isso nos remete ao fato de que constituir-se em um ser é o resultado de mudanças expressivas que se dão ao longo da trajetória humana, cujas marcas nem sempre são aceitas de forma passiva ou afetivamente positiva.

As experiências, as relações com os pares e as percepções vivenciadas durante a infância pela criança, pouco a pouco "acumulam-se" para arquitetarem o homem adulto. Todavia, devemos ressaltar que o meio social é um fator indispensável para a manifestação desse crescimento. Wallon observa o desenvolvimento de um sujeito como uma edificação progressiva em que acontecem fases com predominância, alternadamente, afetiva e cognitiva. Afetividade defendida nesse texto como a capacidade humana de o sujeito ser afetado pelo que ocorre ao seu entorno, de se sensibilizar com e para com o outro, ao mesmo tempo em que pode ser fruto de um experienciar agradável ou desagradável.

Esse processo de edificação de um indivíduo passa também pela linguagem, que exerce um papel preponderante na constituição dos sujeitos. Sobre esses aspectos, o autor relata que:

[...] sem a linguagem, não há nenhuma possibilidade de representar a ordem mais insignificante, de efetuar uma sequência. Dela depende também o poder de ordenar as sucessivas partes do discurso. [...] ela não é, verdade se diga, a causa do pensamento, mas é o instrumento e o suporte indispensáveis aos seus progressos. (WALLON, 1995, p.186).

Destarte, cada etapa tem uma tonalidade própria, uma particularidade, uma unidade significativa, que é dada pela preponderância de um tipo de atividade. Essas atividades predominadoras estão relacionadas aos recursos de que se dispõe, no momento, para interagir com o ambiente.

Vygotsky (1998) e Wallon (1995) construíram suas teorias sobre o desenvolvimento infantil partindo da mesma concepção de ser humano e de realidade. Ambos conceberam o sujeito a partir do materialismo histórico e dialético, entendendo que sua relação com a realidade se dá por meio de mediações que permitem que ele seja transformado pela natureza, que por sua vez é transformada por ele. Assim, a mediação se processa através da utilização de instrumentos e signos que possibilitam, pela interação social, a transformação do meio e dos 
sujeitos. Esses estudiosos, na contramão das concepções dominantes a sua época, procuraram respostas a indagações sobre como as pessoas se relacionavam com o social e de que modo produziam cultura.

\section{OS ESTÁGIOS DO DESENVOLVIMENTO}

A partir dos estudos teóricos e das socializações ocorridas em sala de aula e considerando uma concepção mais concreta do desenvolvimento de um sujeito, a seguir são descritas as minudências centrais de cada um dos cinco estágios nomeados pela psicogenética walloniana.

No estágio impulsivo-emocional, que abrange o primeiro ano de vida (impulsivo: 0 03 meses; emocional: 03 meses a 01 ano), as emoções são o primeiro recurso de interação do bebê com o meio social. É um estágio predominantemente afetivo. A afetividade se sustenta pelo olhar, pelo contato físico, posturas, gestos e expressões. A sucessiva resposta do ambiente permite que a criança passe de movimentos desordenados para sentimentos individualizados.

No estágio sensório-motor e projetivo, que vai até o terceiro ano (sensório-motor: 12 - 18 meses; projetivo: 18 meses a 03 anos), o interesse do recém-nascido está relacionado à cognição da marcha e apreensão. Nesse período, a criança exibe uma maior autonomia na manipulação de objetos e no monopólio dos espaços e o interesse se volta para a exploração sensório-motora do mundo físico.

Durante esse estágio, acontece o desenvolvimento da função simbólica e da linguagem. O termo "projetivo" utilizado para indicar essa fase deve-se à peculiaridade do funcionamento mental neste estágio do desenvolvimento: os pensamentos carecem do subsídio dos gestos para se exteriorizar.

No estágio do personalismo, que sucede dos três aos seis anos, a criança começa a desenvolver e a construir novos protótipos, apresenta uma consciência de si por intermédio das interações sociais, reorientando o interesse pelas pessoas. A formação da personalidade é a característica central desse período, com predominância das relações afetivas. Nesse estágio, a afetividade está ligada ao simbólico (linguagem), que se exprime por palavras e ideias.

A partir dos seis anos, inicia-se o estágio categorial, com importantes avanços no plano da inteligência. As evoluções intelectuais conduzem o interesse das crianças para as situações rotineiras, para o conhecimento e para a conquista do mundo exterior. Nessa fase, suas interações com o meio têm a preponderância cognitiva. 
No estágio da predominância funcional, incide uma nova acepção das adjacências da personalidade, desestruturadas devido às transformações fisiológicas e corporais resultantes da ação hormonal. Questões de natureza pessoal, moral e existencial são trazidas à tona. Podemos ressalvar que é um período singular da vida dos indivíduos, em que eles questionam os valores sociais, buscando maneiras de encontrarem-se e posicionarem-se diante dos outros. Os referidos estágios possuem peculiaridades que oferecem um conjunto de indícios orientadores da ação docente, sinalizam características ou ausências que podem contribuir para a avaliação do ensino-aprendizagem e reestruturar o planejamento do professor, redirecionar esforços e melhorias na aprendizagem e desenvolvimento dos alunos.

\section{OS DOMÍNIOS FUNCIONAIS}

Os domínios funcionais são identificados por Wallon (1995) como as fases vivenciadas pelas crianças: afetividade, motricidade (ato motor ou psicomotor), conhecimento (cognição) e pessoa completa (Figura 1). Neste aspecto, ele ressalta que a emoção é o vínculo primário a ser estabelecido entre as pessoas, sendo essencial a percepção dos gestos, das mímicas, do olhar, da expressão facial enquanto características típicas da atividade emocional.

A afetividade assinala para três períodos: emoção, sentimento e paixão. Nesse contexto, Galvão (2007, p.6) ressalta que: "a afetividade refere-se à capacidade, à disposição do ser humano de ser afetado pelo mundo externo/interno por sensações ligadas a tonalidades agradáveis e desagradáveis", o que distingue do escólio de senso comum, que normalmente decodifica afetividade como apenas afetuosidade ou carinho.

Figura 1 - Diagrama da constituição da pessoa completa.

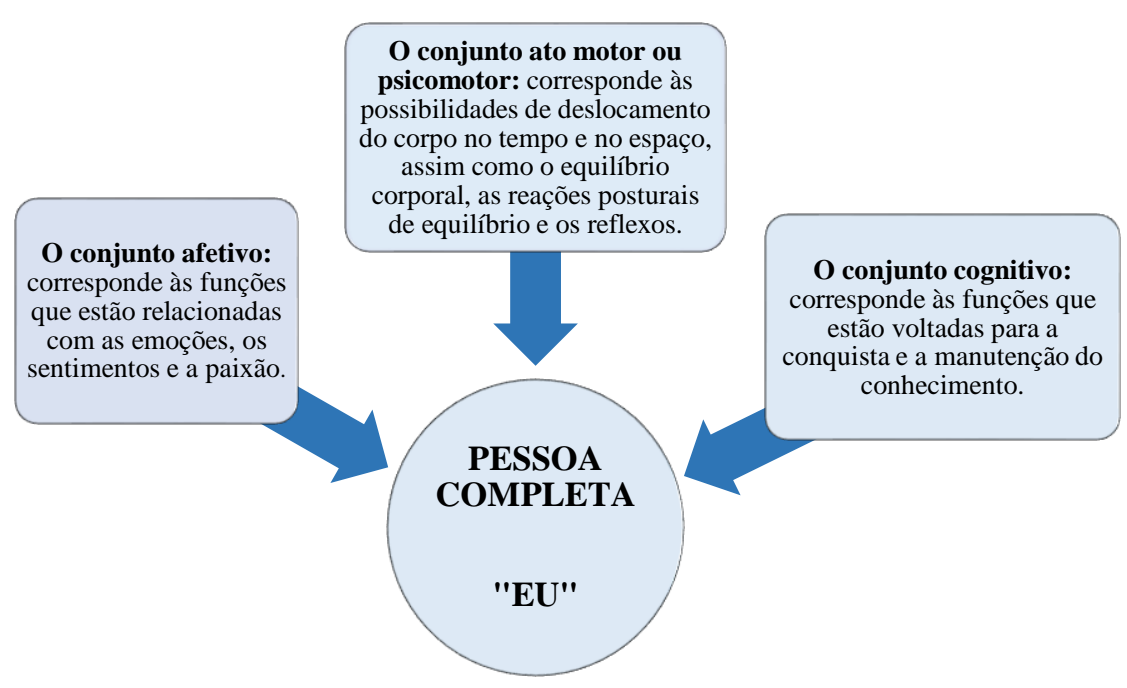

Fonte: Elaboração dos autores com base em Wallon (1995). 
O algoritmo corporal das emoções é o que evidencia a teoria walloniana, ao aclarar que os sentimentos podem ter um acoplamento recíproco entre o tônus, o movimento e a função postural. Para o autor, as conjunturas afetivas são prazerosas porque o fluxo tônico aumenta e se dimana posteriormente com movimentos significativos. Deste modo, uma condição de desequilíbrio ou colapso emocional tem "colisão" direta com as ações. Sob o efeito de emoções descontroladas, também submerge o comando das ações.

No estágio do personalismo, acontece um desdobramento das emoções, objetivando a cognição da identidade. A criança se revela em aversão ao outro, proferindo a expressão "não" a tudo e a todos, e aprende a demarcar o que é ela e o que é o seu par, principiando a utilização de pronomes (eu, meu, teu).

Mas, ao mesmo tempo, verifica-se a intensa dependência da criança em relação aos seus familiares. Esses períodos de oposição intercalam-se com momentos de encanto, alegria e prazer nos quais a criança busca a aceitação e a admiração dos outros, por muitas vezes imitando os adultos nas brincadeiras de faz-de-conta, nos jogos de papéis sociais, nas demais atividades lúdicas. Assim, é preciso que ela se sinta acolhida, respeitada pelos adultos e pelas demais crianças com quem convive e tenha possibilidades de brincar. Para Wallon (1995), a brincadeira proporciona condições de ações da criança no mundo que a circunda - material ou das pessoas, assimilando-o enquanto se faz parte dele. A esse respeito, em investigação científica à luz da teoria de Wallon, sobre a relação família-criança por meio das brincadeiras infantis, as pesquisadoras Haddad e Maynart (2017) constataram que

Nas brincadeiras que envolvem papéis familiares e relações de parentesco, as crianças trazem elementos da macrocultura que funcionam como um substrato para o processo de produção de significados. A cada papel desempenhado, associam-se funções, atribuições e regras que são realizadas, confrontadas, negociadas e ressignificadas no entrejogo de modos de agir, pensar e sentir de cada criança individualmente e o sistema de crenças e teorias do mundo simbólico-cultural e passa, necessariamente, pelas interações sociais com o outro. (HADDAD; MAYNART, 2017, p. 79).

Essas considerações são fundamentais para a atividade do professor, desde a compreensão do desenvolvimento da afetividade da criança, que se estabelece na unidade entre o corpo e as emoções, o qual envolve toda psicogênese até as ações, por meio das quais, ela assimila as regras sociais, as relações entre as pessoas e seus papéis na sociedade, atribuindo significados enquanto consumidora e, também, produtora da cultura humana.

Um outro aspecto a destacar sobre os domínios funcionais da teoria walloniana é o movimento. O movimento constitui a primária revelação na vida de um ser humano, pois desde o início da vida intrauterina conseguimos nos mover, e dessa forma vão se estruturando e 
desempenhando admiráveis influências no comportamento. Assim, é importante assegurarmos à criança o desenvolvimento funcional, haja vista que os movimentos expressam os nossos sentimentos e emoções, as nossas percepções e pensamentos. São várias as significações que Wallon confere ao ato motor ou psicomotor.

“Além do seu papel na relação com o mundo físico (motricidade de realização), o movimento tem um papel fundamental na afetividade e também na cognição" (GALVÃO, 1995, p.69). Antes de operar diametralmente sobre o meio físico, o movimento atua sobre o ser humano, mobilizando-o por meio das emoções. Nas crianças, o ato psicomotor é tudo o que pode dar testemunho de sua vida psíquica, pelo menos até o momento em que abrolham as palavras.

O domínio funcional cognitivo proporciona um conjunto de funções que comporta a aquisição e a sustentação do conhecimento por meio de fotos, imagens, gráficos, observações, ideias e representações. Nesse domínio, é possível historiar, anotar e rever o passado, adsorver e avaliar o presente e lançar-se para futuros aceitáveis e imaginários.

Em relação à pessoa, expressa-se uma integração de todos os outros conjuntos, em todas as suas vertentes e possibilidades. Em todas as etapas do desenvolvimento humano, é presumível identificar atributos distintos: precisões e interesses que lhe avalizam coerência e integração. A cada estágio, institui-se um tipo de relação/interação entre a criança e o meio. $\mathrm{O}$ meio não é estático, é dinâmico e transforma-se juntamente com a criança.

Wallon acreditava que todos os sujeitos careceriam de ter oportunidades análogas, até mesmo em respeito à singularidade, e para isso seria imprescindível haver escola para todos em que cada um pudesse encontrar, conforme suas competências e habilidades, todo o desenvolvimento intelectual e moral que fosse adequado para aprender e assimilar. Acreditava que, proporcionada uma base comum, dever-se-ia também oportunizar condições para que as crianças, experimentando e vivenciando, descobrissem suas convergências de acordo com seu estágio de desenvolvimento.

Para o teórico, o sujeito completo só é arquitetado em sua forma universal conferindolhe o poder de conhecer, vivenciar, compreender, avaliar e escolher. Uma educação humanista deve apreciar todas as acomodações que formam a pessoa completa, visto que potencialmente um sujeito pode se desenvolver em quaisquer direções, a depender de sua magnificência biológica e das condições em que vive. Ressaltamos, neste contexto, o professor que, em sala de aula, confronta resultados teórico-práticos com o uso da sensibilidade do olhar ao outro, do ser curioso que, na curiosidade, atende, indaga, observa e se observa em atividade. Assim, a teoria do desenvolvimento walloniano se concretiza em direções e derivações didáticas 
importantes: a primeira possibilita prever as atividades, as tarefas de estudo, as ações para ensinar e aprender, a segunda orienta e substancia as indagações, as perguntas norteadoras e, não menos importante, a terceira direção como possibilidades reais de atuação com autonomia.

A escola é um elemento das condições de existência na qual a pessoa interage, desenvolve, aprende e se organiza. Partindo dessas pressuposições, as propostas educacionais careceriam de ser conduzidas de maneira que todas as aptidões pudessem ser orientadas e lavradas segundo sua natureza, de forma que o ensino recebido fosse uma preparação suficiente para o exercício de qualquer função que poderia oferecer-se mais tarde. Por isso é preciso dotar o homem de uma cultural geral que o proporcione pensar, estabelecer relações entre os diversos campos do saber, viver, interagir e intervir em sua realidade.

A teoria walloniana pode contribuir de maneira significativa para a Didática, enquanto área científica responsável pela produção de conhecimentos sobre/do processo de ensinoaprendizagem e as práticas pedagógicas que são desenvolvidas nas instituições escolares e, principalmente, nos cursos de formação de professores, pois o estudo da criança não é um simples instrumento para o entendimento do psiquismo humano, mas uma fonte importante de conhecimentos para atuação docente.

A teoria em foco é constituída de procedimentos que permitem ampliar as concepções dos docentes sobre as possibilidades dos estudantes no processo ensino-aprendizagem. Nesse sentido, a teoria walloniana fornece subsídios para a reflexão sobre a prática pedagógica - de como a educação pode criar condições para oportunizar esse processo -, possibilitando a aprendizagem de novos comportamentos, percepções, ideias e valores como também "aguçando" a investigação educacional. Para Wallon, a formação psicológica do indivíduo e a prática pedagógica dos professores não podem ficar limitadas aos livros. Devem ter referência, também, nas experiências pedagógicas que eles próprios podem realizar.

Corroborando o exposto, Pérez Gómez (1998, p.43) discorre sobre a ênfase que Wallon dá à motivação intrínseca e seus desdobramentos no ensino.

A dissociação entre afetividade e pensamento é metodológica, artificial e não pode transformar-se num princípio de procedimento na escola. Toda a atividade cognitiva da criança implica, em sua origem, seu desenvolvimento, ou sua conclusão, inevitáveis componentes afetivos que por si mesmos impulsionam a aprendizagem. Quando o ensino recorre a motivações extrínsecas é preciso perguntar-se o quanto separadas estão, as tarefas empreendidas, da realidade vital que preocupa o sujeito.

Neste caso, a organização do ensino e os recursos didáticos selecionados pelo professor, os objetivos de aprendizagem, os procedimentos e as estratégias de ensino ganham 
relevância nessa perspectiva teórica, ao se considerar necessária a motivação do aluno no processo de aprender e compreendê-lo para além das fragmentações, como um ser completo.

O processo cognitivo não acontece por justaposição, mas por reorganização do conhecimento, que é "provisório", uma vez que não é possível chegar de imediato ao conhecimento desejado, mas somente por aproximações sucessivas que permitem sua reconstrução. Nessa perspectiva, os erros são entendidos como estratégias usadas pelo aluno na sua tentativa de aprendizagem de novos conhecimentos, portanto, inerente ao processo de aprendizagem. A superação do erro é resultado do processo de incorporação de novas ideias e de transformação das anteriores, de maneira a dar conta das contradições que se apresentarem ao sujeito para que, assim, alcance níveis superiores de conhecimento. A teoria psicogenética walloniana lança luz à questão dos diferentes estilos individuais de aprendizagem; reforça a importância do "outro" na aprendizagem como fator decisivo nas experiências do indivíduo.

Os companheiros de sala e os materiais didático-pedagógicos poderão contribuir para que a aprendizagem se realize, mas nada pode substituir a atuação do próprio aluno na tarefa de construir significados sobre os conteúdos da aprendizagem. É ele quem modifica, enriquece e, portanto, constrói novos e mais potentes instrumentos de aprendizagem. Neste contexto, a prática docente torna-se imprescindível tanto do ponto de vista da organização do ensino que possibilite a participação efetiva do aluno, como na possibilidade de mediação do processo ensino-aprendizagem. As metodologias utilizadas devem direcionar-se para a atuação do aluno contrapondo à passividade como no modelo de ensino tradicional. $\mathrm{O}$ professor precisa ter claramente o que almeja com a sua prática, qual aprendizagem os alunos devem conseguir, quais conhecimentos, habilidades e capacidades devem ser desenvolvidas, para assim, contribuir com esse desenvolvimento.

Diante do exposto, podemos depreender que os pressupostos wallonianos vão ao encontro de uma sociedade pautada na igualdade de oportunidades ao propor o desenvolvimento da totalidade do sujeito. Aqueles são ferramentas psicológicas que podem proporcionar a compreensão do outro cultural, do nascimento à morte, todo movimento de ser, estar e se fazer humano. A escola e a educação que ali se realiza necessariamente precisam ser ressignificadas nesta perspectiva, não cabendo diferenciações entre intelecto e prática se se quiser uma educação com base na justiça e na igualdade. Isso torna temerária a escola que privilegie classes sociais, o ensino-aprendizagem excludente, que, mesmo não se conformando, conforma-se à perpetuação elitista de segregação cultural. 


\section{CONSIDERAÇÕES FINAIS}

Wallon contribuiu de forma significativa para a Educação. Sua teoria é um instrumento que pode alargar a compreensão sobre as possibilidades do educando no processo ensinoaprendizagem e prover informações para reflexões de como o ensino pode instituir intencionalmente condições para beneficiar esse processo, adequando a aprendizagem de novos comportamentos e conhecimentos, novas ideias e valores.

Para o autor, o meio e a cultura experienciada influenciarão os valores morais e sociais que a criança irá incorporar devendo serem cultivados os valores de solidariedade e justiça.

Em suas obras, a afetividade constitui um domínio funcional expressivo, tanto quanto a inteligência. Afetividade e inteligência compõem um par intrínseco na evolução psíquica, pois, embora apresentem funções bem definidas e individualizadas entre si, são interdependentes em seu desenvolvimento, permitindo à criança atingir níveis de evolução cada vez mais elevados.

Para Wallon, o educador é antes de tudo, um pesquisador, um observador que irá criar oportunidades e atividades para que a criança possa se desenvolver integralmente. A passagem dos estágios de desenvolvimento não ocorre de forma linear, por ampliação. Ela acontece por reformulação, abrigando-se nos períodos da passagem de uma etapa a outra, e por crises que irão afetar a conduta da criança.

Por meio da organização do processo de ensino-aprendizagem, o docente encontra recursos para abarcar os caminhos censuráveis da aprendizagem, e o papel da afetividade é um componente importante no sentido de garantir o êxito nessa enorme ação: ensinar.

Em síntese, podemos afirmar que tanto a organização do ensino de conteúdos escolares como as estratégias didáticas utilizadas pelo professor precisam levar em conta as contribuições das teorias de aprendizagem, tomando-as como fundamento psicológico do ato de aprender.

\section{REFERÊNCIAS}

GALVÃO, I. Henri Wallon: uma concepção dialética do desenvolvimento infantil. Petrópolis: Vozes, 2007.

HADDAD, Lenira; MAYNART, Renata da Costa. A compreensão de relações familiares pelas crianças em situação de brincadeira em contexto de educação infantil. Revista Zero-aseis. ISSN 1980-4512, vol. 19, n. 35, p. 69-81, jan-jun 2017.

MAHONEY, Abigail A.; ALMEIDA, Laurinda R. A constituição da pessoa na proposta de Henri Wallon. São Paulo: Loyola, 2004. 
PÉREZ GÓMEZ, Antonio I. Os processos de ensino-aprendizagem: análise didática das principais teorias da aprendizagem. In: SACRISTÁN, José Gimeno e PÉREZ GÓMEZ, Antonio I. Compreender e transformar o ensino. 4. ed. Porto Alegre: ArtMed, 1998, p. 27-51.

TRAN-THONG. Estádios e conceitos de estádio de desenvolvimento da criança na psicologia contemporânea. Lisboa: Aprofundamento, 1987. $2 \mathrm{v}$.

VYGOSTKY, Lev S. A formação social da mente. São Paulo: Martins Fontes, 1998.

WALLON, Henri. A evolução psicológica da criança. 2.ed. Lisboa, Portugal: Edições 70, 1995.

\section{SOBRE OS AUTORES}

Ricardo Baratella é doutorando em Educação pela Universidade de Uberaba. Mestre em Educação pela Universidade de Uberaba. Graduado em Pedagogia pela Universidade de Uberaba. Licenciado em Ciências - Habilitação Plena em Biologia e Licenciado em Ciências - Licenciatura de Primeiro grau pela Faculdade de Filosofia, Ciências e Letras Barão de Mauá. Gestor do curso de Licenciatura em Ciências Biológicas e Professor da Uniube.

E-mail: gestor.cienciasbiologicas@uniube.br

Adriana Rodrigues é Doutora em Educação pela Universidade Federal de Uberlândia (UFU). Professora na Universidade de Uberaba (UNIUBE).

E-mail: adriana.rodrigues@uniube.br 